\title{
S5ynthesis
}

International Scientific Conference of IT and Business-Related Research

\section{MODELI I PRIMENA EKSTERNE MENADŽMENT PODRŠKE U MALIM PREDUZEĆIMA}

\section{MODELS OF EXTERNAL MANAGEMENT SUPPORT IN SMALL ENTREPRISES}

\author{
Božidar Leković, Slobodan Marić \\ Univerzitet u Novom Sadu, Ekonomski fakultet Subotica, Departman za menadžment, Segedinski put 9-11, Subotica, Srbija
}

\begin{abstract}
Apstrakt:
Pored nedvosmislenog iskazivanja i prepoznavanja potrebe za menadžment praksom u malim preduzećima, od strane vlasnika/ preduzetnika/menadžera, postoje brojni razlozi i ograničanja zbog kojih ovaj vid podrške ostaje nedostižan na putu uspeha malih preduzeća. Osnovni nedostatak i ograničenje dostupnosti brojnih resursa ovoj vrsti privrednih subjekata, jeste pre svega veličina, koja je osnovni ograničavajući faktor u smislu raspoložive finansijske snage kako bi se obezbedili osnovni preduslovi rasta. Usled ovakvih okolnosti značajan deo ljudskih potencijala kojima malo preduzeće raspolaže, u vidu znanja, veština i sposobnosti, treba da pruži sam vlasnik/preduzetnik/menadžer. Čak i kada postoji svest o potrebi dobre menadžment prakse za uspešno poslovanje malog preduzeća i nedostatku ovih sposobnosti kod samog preduzetnika, angažovanje profesionalnih menadžera nije dostižna mogućnost u ovoj fazi razvoja. Zbog brojnih razloga koje ćemo kasnije obrazložiti, najbolji izbor u skladu sa resursnim potencijalima privrednih subjekata, u ovoj fazi razvoja, predstavlja eksterna menadžment podrška malim preduzećima $\mathrm{u}$ ad hoc formi. Osnovna namera ovog rada je ispitivanje spremnosti prihvatanja eksterne menadžment podrške od strane vlasnika/preduzetnika/menadžera kao i međuzavisnost eksterne menadžment podrške i poslovnog uspeha tj. učinka malih preduzeća.
\end{abstract}

\section{Ključne reči:}

mala preduzeća, profesionalni menadžment, eksterna podrška.

\section{UVOD}

Menadžment praksa u malim preduzećima predstavlja jednu od glavnih nezavisnih varijabli ovog istraživanja. Postoje različiti pristupi i opredeljenja u poimanju ovog dela istraživanja. Po Vikamu prisustvo menadžmenta malim preduzećem kod preduzetničkih poduhvata potvrđuje se strategijskom orijentacijom što predstavlja osnovni indikator menadžment prakse u malim preduzećima (Wickham, 2004). Suštinski strategijska orijentacija podrazumeva postojanje dugoročnog opredeljenja malih preduzeća za ostvarivanje poslovnih aktivnosti koje su opredmećene u strategijskim ciljevima i definisane misijom i vizijom poslovanja. Prisustvo formalnog menadžmenta u malim preduzećima u značajnoj meri identifikuje se sa planskim aktivnostima. Dominantna aktivnost u okviru strategijskog menadžmenta je planiranje. Kao prva faza procesa menadžmenta, planiranje je definitivno ključna tema kada su u pitanju mala preduzeća i menadžment praksa. Pojedini autori planiranje dovode u vezu sa unapređenjem učinka (performansi), dok ga drugi tretiraju kao ključni faktor uspeha. Vezivanje menadžment prakse isključivo za planske aktivnosti daje nam naznake da se radi o početnim fazama menadžment sistema i njegovog razvoja u ma-

\section{Abstract:}

Besides unequivocal necessity and readiness of owners, entrepreneurs and managers to accept external management support in small-sized enterprises, there are numerous reasons and factors that make this type of support unattainable for such enterprises on their path towards success. The main factor causing lack of resource availability to these business entities is primarily the size, as the main limiting feature in terms of available financial strength to provide the basic growth prerequisites. Due to these circumstances, a considerable part of human resources the company disposes of in terms of knowledge, skills and abilities, needs to be provided by the owner, entrepreneur, and manager. Even if there is the awareness about the necessity for good management practices for successful performance of small-sized enterprises, but the entrepreneurs are missing such skills, it would be desirable to hire professional managers. Unfortunately, this would be impossible at this development stage. Due to numerous reasons that shall be further explained and in accordance with the resource potentials of business entities, the best option is ad hoc external management support to small-sized enterprises. The purpose of this paper is to examine the readiness of owners, entrepreneurs and managers to accept external management support, as well as to analyze interdependence between external management support and business success i.e. performance of small-sized enterprises.

\section{Key words:}

small-sized enterprises, professional management, external support.

lim preduzećima, shodno nivou poslovnih aktivnosti privrednih subjekata. O značaju poslovnog planiranja za mala preduzeća govore i sledeći citati. Ako se preduzetnik početnik obrati za savet vezano za unapređenje poslovanja odgovor će najčešće biti „počnite sa planiranjem“ (Brinckmann et al., 2010). Takođe, na većini univerziteta koji imaju studijske programe preduzetništva studenti uče o značaju planiranja i izradi biznis planova (Brinckmann et al., 2010). Od prvih 100 poslovnih škola u SADu, 78 škola ima kurseve o izradi poslovnih planova (Honig, 2004). Vodeći profesori iz oblasti preduzetništva smatraju da je razvoj biznis planova najznačajnija metodska jedinica nastave iz preduzetništva (Hills, 1988). U mnogim zemljama poslovni plan predstavlja jedan od glavnih istrumenata za razvoj preduzetništva kao i regionalni razvoj (Russel et al., 2008; Lange et al., 2007). Takođe, brojni primeri ukazuju na to da svake godine na stotine osoba učestvuje u vladinim programima obuke za izradu poslovnog plana (Brinckmann et al., 2010). Navodeći ove stavove još uvek nismo precizno definisali šta podrazumevamo pod menadžment praksom u malim preduzećima. Kada je reč o prethodnom pitanju postoje dve suprostavljene škole: škola planiranja i škola učenja (Wiltbank et al., 2006). Zagovornici planske škole ističu da planiranje unapređuje efikasnost i uči- 
nak malih preduzeća (Ansoff, 1991). Armstrong (1982) i Porter (1985) kao glavne komponente poslovnog planiranja navode: strategijske ciljeve, strategiju, evaluaciju i odlučivanje, kao deo implementacije i kontrole. Pristalice škole učenja stavljaju naglasak na učenje, strategijsku fleksibilnost i kontrolu resursa, a ne na predefinisano ponašanje $u$ vidu formalnog plana (Mosakowski, 1997; Mintzberg, 1994).

Ukoliko izuzmemo uspešnost prethodnih napora, zaključak ovog istraživanja je da se menadžment praksa u malim preduzećima, u obimu i kvalitetu u kojem je prisutna, nalazi u pozitivnoj korelaciji sa uspehom/učinkom malih preduzeća. Zbog brojnih razloga koji će kasnije u ovom radu biti izloženi, prirodni izvor, u skladu sa resursnim potencijalima privrednih subjekata, u ovoj fazi razvoja predstavlja eksterna menadžment podrška malim preduzećima, dominantno u ad hoc formi.

\section{MENADŽMENT PODRŠKA MALIM PREDUZEĆIMA}

Pored nedvosmislenog iskazivanja i prepoznavanja potrebe za menadžment praksom u malim preduzećima od strane vlasnika/preduzetnika/menadžera, postoje brojni razlozi i ograničanja zbog kojih ovaj vid podrške ostaje nedostižan na putu uspeha malih preduzeća. Osnovni nedostatak koji ograničava prisupt brojnim resursima kod ovakvog tipa privrednih subjekata jeste pre svega veličina, koja je osnovni ograničavajući faktor u smislu raspoložive finansijske snage kako bi se obezbedili osnovni preduslovi rasta. Usled ovakvih okolnosti značajan deo ljudskih potencijala (znanje, veštine, sposobnosti) kojima raspolaže malo preduzeće trebalo bi da pruži sam vlasnik/preduzetnik/menadžer. Čak i kada postoji svest o potrebi za dobrom menadžment praksom koja predstavlja preduslov za uspešno poslovanje malog preduzeća, nedostatak ovih sposobnosti kod samog preduzetnika i angažovanje profesionalnih menadžera nije moguće u ovoj fazi razvoja. Kako bi se prevazišao jaz između potreba i mogućnosti, jedno od rešenja može biti eksterna menadžment podrška malim preduzećima. Najčešći izvor menadžerske pomoći preduzetnici mogu pronaći u okviru poslovnih inkubatora, vladinih programa i kod profesionalnih menadžment konsultanata. Nisu retki ni pokušaji preduzetnika da do znanja i iskustva koje im nedostaje dođu putem specijalizovanih kurseva obuke na fakultetima.

Uloga i funkcija poslovnih inkubatora kao dela preduzetničke infrastrukture za pružanje podrške u pokretanju i vođenju poslovnih poduhvata je veoma fleksibilno postavljena i prihvaćena, što je značajno uticalo na konceptualizaciju teorijske ideje u konkretne merljive poduhvate. U većini praktičnih primera možemo zaključiti da je prisutna samo forma dok se suštinska funkcija i smisao ne mogu pronaći, što potvrđuju konkretni rezultati dosadašnjeg poslovanja pojedinih poslovnih inkubatora. Jedan od sveobuhvatnijih pogleda na ulogu i funckiju inkubatora u potpunosti oslikava široko poimanje ovog koncepta navodeći inkubatore kao „dodeljene kancelarijske kapacitete, dodatnu strategijsku vrednost u vidu sistema nadzora i poslovne pomoći, sa objektivnim mogućnostima uspešnog razvoja novih poduhvata dok istovremeno preuzima troškove potencijalnog neuspeha, to je mreža indivudualaca i organizacija“ (Hackett \& Dilts, 2004). U okviru teme poslovnih inkubatora aktuelno je pitanje ostvarivanja svrhe postojanja, rezultata poslovanja, kao i način njihovog merenja, koje su u vidu kritičnih fatora uspeha postavili Hackett \& Dilts (2004):

- selekcija i nadzor kandidata;

- pristup kapitalu;

- konstantna poslovna ekspertiza;
- precizno definisane smernice sa jasnim politikama i procedurama tokom perioda inkubacije.

U značajnoj meri, odgovor na prethodno pitanje dobija se preciznim definisanjem životnog ciklusa inkubatora, odnosno razvojnih faza. U narednom prikazu vide se osnovni rezultati poslovnog inkubatora u zavisnosti od trenutne faze razvoja. Upravo analiza životnog ciklusa inkubatora omogućava da se postigne ono što nedostaje u smislu glavnih rezultata, obezbeđujući indirektnu procenu u okviru odnosa između životnog ciklusa i rezultata inkubatora. Mnogi autori potvrđuju da razvoj inkubatora kroz životni ciklus menja svoj fokus, a samim tim i program izbora, prijema i politiku podrške.

\begin{tabular}{|c|c|c|}
\hline Faza & Profil & Komentar \\
\hline Start up & $\begin{array}{l}\text { Održavanje visoke stope je primarna } \\
\text { briga: } \\
\text { - Start up kao što su i ostali } \\
\text { poduhvati u poslovanju (najviše } \\
\text { do } 3 \text { godine) se prihvataju; } \\
\text { Ne moraju biti prethodno } \\
\text { definisanog poslovnog profila ili } \\
\text { sektorske orijentacije da bi bili } \\
\text { prihvaćeni; } \\
\text { Menadžer poslovnog inkubatora } \\
\text { nije u prilici da posveti mnogo } \\
\text { pažnje početnim poslovnim } \\
\text { poduhvatima; } \\
\text { Prelomna tačka rentabiliteta je } \\
\text { postignuta kada se ostvari pot- } \\
\text { puna ili skoro potpuna zauzetost; }\end{array}$ & $\begin{array}{l}\text { Potrebe za } \\
\text { tekućim } \\
\text { sredstvima } \\
\text { su najveće } \\
\text { na ovom } \\
\text { nivou. }\end{array}$ \\
\hline $\begin{array}{l}\text { Nivo } \\
\text { razvoja } \\
\text { poslovanja }\end{array}$ & \multicolumn{2}{|c|}{$\begin{array}{l}\text { Ostvarena visoka stopa iskorišćenosti (zauzetosti) i } \\
\text { pažnja preusmerena sa razvoja vlasništva na razvoj } \\
\text { preduzeća. } \\
\text { Ovo postaje veoma značajno u procesu selekcije } \\
\text { kandidata: } \\
\text { - Unapređenje učestalosti interakcije između } \\
\text { menadžera inkubatora i kandidata; } \\
\text { - Više pažnje je posvećeno potrebama postojećih } \\
\text { kandidata nego novoodabranim; } \\
\text { - Sinergija se razvija sa umrežavanje kandidata } \\
\text { ili ukoliko centralna podrška nije dovoljna ili } \\
\text { relevantna; } \\
\text { - Stabilna tražnja za prostorom u okviru inkuba- } \\
\text { tora. }\end{array}$} \\
\hline Zrelost & \multicolumn{2}{|c|}{$\begin{array}{l}\text { Potražnja za upotrebom većeg prostora i kandidati } \\
\text { imaju potrebu za sveobuhvatnijom uslugom: } \\
\text { Ulazni i izlazni kriterijumi postaju strogi; } \\
\text { Nedostatak prostora zbog visoke tražnje za } \\
\text { prijemom novih kandidata i rastuće potrebe } \\
\text { postojećih kandidata vode inkubatore ka } \\
\text { proširenju. }\end{array}$} \\
\hline
\end{tabular}

Prikaz 1. Životni ciklus poslovnog inkubatora Izvor: Hamdani, D. (2006).

Tako je u početnoj fazi razvoja inkubatora mnogo bitniji stepen popunjenosti prostora (kapaciteta) nego strikno definisanje politike prijema, jer mnogi autori ističu da se odnos stope popunjenosti inkubatora često koristi kao pokazatelj učinka. Ono što se ukratko može sumirati iz predhodnog prikaza, po pojedinim fazama u razvoju inkubatora, jeste da u okviru početne faze razvoja ne postoje precizno definisani kriterijumi prijema, te da je kandidatima posvećena daleko manja pažnja od očekivane. U fazi razvoja poslovanja ističe se potpuna ili skoro potpuna popunjenost, pa glavni fokus postaje preduzetnički razvoj. U fazi zrelosti prisutna je potražnja za proširenjem kapaciteta, što dovodi do širenja inkubatora. Iz ovog kratkog predstavljanja ključ- 
nih faza u razvoju inkubatora mogu se predvideti potencijalni ishodi nakon svake faze. Takođe se može videti da inkubatori u zrelijim fazama životnog ciklusa pružaju mnogo više dodatnih vrednosti nego u početnim razvojnim etapama.

Način na koji poslovni inkubatori doprinose oblikovanju poslovnih ideja u uspešne poslovne poduhvate isključivo zavisi od njihove konceptualizacije. Tokom vremena, inkubatori su posmatrani kao društveni razvojni programi, mehanizmi komercijalizacije i transfera tehnologije ka preduzetništvu. Glavni doprinos poslovnih inkubatora ogleda se u funkciji koja se odnosi na pružanje pomoći novim poduhvatima u ranim fazama poslovanja, budući da osnivanje novih preduzeća zahteva određenu kombinaciju resursa kao i organizacione, menadžment, tehnološke i tržišne kompentencije u cilju zadovoljenja nepredviđenih potreba i tražnje. Iako je proces kreativne destrukcije, koji je definisan u okviru teorije ekonomskog rasta, imanentan tržišnim ekonomijama, studije iz oblasti inovacija ukazuju na to da šanse za uspešnu implementaciju poslovnih ideja mogu biti značajno unapređene kroz formalni proces prethodne analize (skrining) i praćenja (monitoring). Tako oslobođeni resursi mogu biti uspešno apsorbovani od strane neočekivanih ideja koje uz odgovarajuću posvećenost mogu imati veće mogućnosti za uspehom na tržištu. Ne možemo sa sigurnošću tvrditi da je uspeh izvestan, ali možemo unaprediti mogućnosti za postizanje uspeha.

Nakon prethodne analize i praćenja nastupa, kritična funkcija poslovnog inkubatora u smislu identifikovanja početnih poslovnih poduhvata sa odgovarajućim potencijalom koji ispoljavaju određene slabosti u cilju pružanja adekvatne podške za pokretanje i opstanak. Centralno pitanje u ovoj fazi odnosi se na izbor metode za selekciju poslovnih predloga i ideja. U tu svrhu razvijene su dve metodologije. Lumpkin i Ireland (1988) koristili su analizu klastera za identifikaciju kritičnih faktora uspeha početnih poslovnih poduhvata, dok je Ministarstvo trgovine SAD-a, razvilo alat za prethodnu analizu i model kompjuterske simulacije koji nastoji da identifikuje nove poslovne poduhvate i mogućnosti za dostizanje komercijalnog uspeha.

Oba pristupa imaju tri nivoa procesa selekcije:

1. ispituje se atraktivnost poslovnog poduhvata,

2. ispituje se postojanje adekvatne usklađenosti aplikanta i posla,

3. ispituje se da li je inkubacija najbolji način podrške.

Ovi koraci u velikoj meri definišu učinak i uspeh samog koncepta inkubatora koji većina istraživača u ovoj oblasti meri na osnovu iznajmljenog prostora, stepena zaposlenosti, kao i broja preduzetnika koji su uspešno napustili prostor inkubatora, dok su sa aspekta preduzetnika kao korisnika usluge pokazatelji rasta prodaje, zapošljavanja, stopa opstanka, itd.

Navedene činjenice u velikoj meri ukazuju na potencijalne slabosti početnih preduzetničkih poduhvata kao i na ključne momente u procesu pružanja adekvatne podrške u cilju uspešnog funkcionisanja institucionalnog okvira za podršku kao što je inkubator. Uspeh inkubatora se meri uspehom kandidata koji su napustili privilegovano okruženje i stabilno posluju na tržištu. Može se primetiti da je tokom svih faza u procesu inkubacije prisustvo adekvatne poslovne ekspertize ključni faktor uspeha poslovne inkubacije što rezultira uspešnim plasiranjem na tržište.

Studentski konsultantski timovi u sklopu fakulteta i univerziteta formirani su u cilju pružanja pomoći malim preduzećima i sticanja ličnog iskustva. Studentski timovi koje čine studenti viših godina studija ili diplomirani studenti, pod mentorstvom profesora fakulteta, rade zajedno sa vlasnicima malih preduzeća na analizi poslovanja i pronalaženju rešenja za aktuelne poslovne probleme.
Značajnu institucionalnu podršku u pružanju eksterne pomoći malim preduzećima predstavljaju razvojni centri koji su podržani i finansirani u okviru vladinih programa. Na primeru Republike Srbije to je nekad bila Republička agencija za razvoj malih i srednjih preduzeća i preduzetništva, a danas je aktuelna Nacionalna agencija za regionalni razvoj čije aktivnosti i usluge podrške odgovaraju svetskim primerima kao što je američka vladina agencija koja obezbeđuje podršku malim preduzećim SBA (US Small Business Administration). Veoma dobar primer pružanja podrške vlasnicima/preduzetnicima/menadžerima malih preduzeća u vidu neophodnog znanja i iskustva po pitanju samostalnog vođenja poslovanja predstavlja američka organizacija SCORE (Service Corps of Retired Executives). $S C O R E$ je organizacija penzionisanih poslovnih stručnjaka iz različitih oblasti poslovanja koji u okviru pomenute organizacije pružaju konsultantske usluge menadžerima malih preduzeća. Ova organizacija se delimično finansira pod pokroviteljstvom SBA (US Small Business Administration), ali i značajnog broja partnerstava. SCORE funkcioniše po principu obostrane koristi budući da penzionisanim poslovnim ljudima omogućava učešće u poslovnom svetu dok menadžeri malih preduzeća u okviru ove organizacije pronalaze kvalitetna rešenja za svoje probleme.

Profesionalni menadžment konsultanti na isti način pružaju usluge malim preduzećima i velikim korporacijama. Međutim, potrebno je napomenuti da vlasnici/preduzetnici/menadžeri malih preduzeća izbegavaju eksterne usluge savetovanja zbog mnoštva razloga. Često preovlađuje mišljenje i verovanje da oni mogu sami da reše problem bući da niko spolja nije toliko upoznat sa poslovanjem ili jednostavno savetodavne usluge iziskuju velike troškove. Možda je osnovna prepreka i razlog za odustajanje od eksterne savetodavne usluge nerazumevanje menadžmenta, odnosno kada kod vlasnika/preduzetnika/menadžera ne postoji svest o potrebi za unapređenjem menadžment prakse u poslovanju i prevelika posvećenost tehnološkom procesu kome se pridaje ključna uloga u dostizanju poslovnog uspeha. Ova se pojava javlja pre svega kod vlasnika/preduzetnika/menadžera tehnološkog ili inženjerskog profila koji zbog nepoznavanja područja menadžmenta, zbog prethodnog obrazovanja i čvrste inženjerske ustrojenosti poslovni uspeh mere kvalitetom i fukcionalnošću sopstvenog proizvoda, zanemarujući tržišne aspekte poslovanja i cost-benefit analizu poslovnih procesa.

Preduzetnička udruženja organizacija koja su u svetu prisutna u formi preduzetničkih mreža (entrepreneurial networ$k s)$ predstavljaju značajan zvor menadžment podrške, znanja i iskustva koja se ostvaruju putem direknih i ličnih kontakata sa drugim vlasnicima/preduzetnicima/menadžerima u vidu razmene iskustva i ideja na obostranu korist.

Pored navedenih formi pružanja eksterne, profesionalne menadžment podrške malim preduzećima postoje i mnogi drugi oblici profesionalnih i poslovnih grupa/udruženja kao što su: bankari, ovlašćene javne računovođe i revizori, agenti osiguranja, dobavljači, trgovinske asocijacije, privredne komore i sl. U svakom slučaju, bez obzira na brojne mogućnosti i izvore savetodavne pomoći i podrške koji egzistiraju u poslovnom okruženju sami vlasnici/preduzetnici/menadžeri moraju biti svesni značaja i vrednosti znanja i iskustava koji su im potrebni. Isključivo oni moraju preduzeti inicijativu za sticanje istih ukoliko u tom pravcu vide i prepoznaju načine za unapređenje poslovanja.

\section{METODOLOGIJA}

Područje istraživanja, odnosno osnovni skup istraživanja ovog rada predstavljaju mala preduzeća u AP Vojvodini-Republika Srbija. Zbog same ekonomičnosti i izvodljivosti istraživačkog posla, što se manifestuje u veličini uzorka, osnovni skup je 
ograničen na geografsko područje AP Vojvodine. Administrativna klasifikacija privrednih društava u Republici Srbiji prema Zakonu o računovodstvu i reviziji (Službeni glasnik RS, br. 46/06 i 111/09), prepoznaje grupu-sektor malih i srednjih preduzeća i preduzetništva. Prema raspoloživim podacima Agencije za privredne registre u grupi malih preduzeća klasifikovano je ukupno 2603 preduzeća. Uzorak na kojem se vršilo istraživanje imaće obeležja proporcionalnog stratifikovanog uzorka. Veličina uzorka u odnosu na osnovni skup iznosi 0.10, odnosno 260 malih preduzeća, što je zadovoljavajuće ako se uzme u obzir broj varijabli zastupljenih u upitniku. Stratifikacija je izvršena na osnovu regiona, kako bi osnovni skup sa prostornog aspekta bio adekvatno zastupljen.

Ono što mala preduzeća čini zvanično prihvaćenim subjektom privredne aktivnosti jeste menadžment orijentacija i iskazivanje namere za dugoročnom egzistencijom i ostvarivanjem sopstvene misije. Postojanje menadžment orijentacije jasno odvaja malo preduzeće od preduzetničkog poduhvata kako je konceptualno pojašnjeno od strane Wickhama (2004). Isto tako početna menadžment praksa, u značajnoj meri, kvalitativno odvaja mala preduzeća od srednjih, kao sledeće adminitrativne faze u razvoju, gde je menadžment prisutan na jednom višem, uglavnom profesionalnom nivou. Zato mala preduzeća odvojena od segmenta srednjih sa isključenom kategorijom mikro preduzeća predstavljaju homogenu celinu, odnosno kvalitativno precizno i jasno omeđeno područje istraživanja. Ono što je obavezujuće u delu koji sledi jeste precizno određenje ključnih varijabli istraživanja kako bi se uzroci, odnosi i veze pojedinih rezultata istraživanja tumačili sa izvesnom dozom pouzdanosti i upotrebljivosti.

\subsection{UPITNIK I SPROVOĐENJE ISTRAŽIVANJA}

Posmatrane promenljive su obeležja (ili varijable). Obeležja u odnosu na koja se deli uzorak na subuzorke su kriterijumska obeležja uspeha/učinaka (C2) i to C2a - opstanak, C2b - rast, C2c - profitabilnost i C2d - razvoj kao zavisna obeležja u vidu kriterijuma za definisanje uspeha malih preduzeća. Više obeležja, koja su međusobno smisleno povezana čine logičnu celinu (C) kao što su C1 - opšte karakteristike vlasnika/preduzetni$\mathrm{ka}$ /menadžera i preduzeća, C3 - upravljačko znanje i formalna upravljačka praksa i C4 - okruženje, zovu se jednostavno "celina" (prostor). Sve posmatrane tematske celine čine prostor istraživanja. Za potrebe ovog rada koriste se podaci koji se odnose na celinu C2 prostora istraživanja.

Osnovni metod koji je korišćen za prikupljanje odgovora na postavljena pitanja je elektronski upitnik (e-survey) uz pomoć Google servisa za elektronsku komunikaciju (google drive) sa ispitanicima (u ovom slučaju vlasnici/preduzetnici/menadžeri malih preduzeća odabranih uzorkom), uzimajući u obzir sve prednosti i nedostatke ove metode. Ispitanici su odabrani slučajnom metodom po principu svaki deseti sa liste formirane od strane Agencije za privredne registre, Vlade Republike Srbije.

\subsection{HIPOTEZA I METODOLOGIJA}

Uvažavajući osnovnu istraživačku nameru, koja je rezultat jasne problemske orijentacije definisane u prethodnom delu rada postavlja se sledeća istraživačka pretpostavka u vidu hipoteze:

H1: Postoji pozitivna korelacija između eksterne menadžment prakse/podrške u malim preduzećima i poslovnog uspeha/učinka.
Za ispitivanje povezanosti i odabranih neprekidnih varijabli prethodno definisanom istraživačkom pretpostavkom koristiće se Pirsonova korelacija. Korelacija ispituje i pokazuje smer (pozitivan ili negativan) i jačinu veze (veličina koeficijenta korelacije (r) uz nivo značajnosti) posmatranih varijabli.

\section{ANALIZA REZULTATA ISTRAŽIVANJA I DISKUSIJA}

Dostupni rezultati istraživanja nakon sprovedene analize omogućavaju ispitivanje istraživačke pretpostavke kao i detaljnu analizu u okviru definisanog područja istraživanja, kroz odabrane varijable. Analiza podataka koji se odnose na područje obrazovanja vlasnika/preduzetnika/menadžera, radno iskustvo, nivo svesti o potrebi menadžment prakse u okviru malih preduzeća, kao i na analizu povezanosti sa pokazateljima uspeha, omogućava da se u potpunosti realizuje istraživačka namera rada.

U pogledu područja obrazovanja (stručnosti) vlasnika/preduzetnika/menadžera u uzorku su zastupljeni: ekonomija, menadžment i biznis sa 100 ispitanika (38,5\%), pravo sa 12 ispitanika (4,6\%), tehničko-tehnološko područje sa 107 ispitanika $(41,2 \%)$, i ostali sa 41 ispitanikom (15,8\%). Iz ovih rezultata područje ekonomije i menadžmenta ima podjednako učešće sa tehničko-tehnološkim obrazovanjem što će biti zanimljivo ispitati sa aspekta sklonosti ka menadžment praksi i potencijalnih razlika u uspehu.

U tabeli 1 analizira se radno iskusvo sa aspekta prethodnog zaposlenja vlasnika/preduzetnika/menadžera. Prisutno je 158 ispitanika sa rukovodećim iskustvom (60,8\%), 74 ispitani$\mathrm{ka}(28,5 \%)$ sa iskustvom radinka izvršioca, dok je bez radnog iskustva 28 ispitanika (10,8\%).

\begin{tabular}{|c|c|c|c|c|}
\hline & $\begin{array}{c}\text { Zastuplje- } \\
\text { nost }\end{array}$ & procenat & $\begin{array}{c}\text { Validan } \\
\text { procenat }\end{array}$ & $\begin{array}{c}\text { Kumula- } \\
\text { tivni } \\
\text { procenat }\end{array}$ \\
\hline 1 Rukovodilac & 158 & 60,8 & 60,8 & 60,8 \\
\hline $\begin{array}{c}\text { 2 Izvršilac, } \\
\text { radnik }\end{array}$ & 74 & 28,5 & 28,5 & 89,2 \\
\hline $\begin{array}{c}\text { 3 Bezradnogi- } \\
\text { skustva }\end{array}$ & 28 & 10,8 & 10,8 & 100,0 \\
\hline Ukupno & 260 & 100,0 & 100,0 & \\
\hline
\end{tabular}

Tabela 1. Prethodno zaposlenje, pozicija, radno mesto Izvor: Kalkulacija autora

U pogledu procene porekla menadžment znanja vlasnika/ preduzetnika/menadžera i strukture izvora validna je tabela 2, gde se vidi da se formalno obrazovanje procenjeno kao izvor vrednuje kod 23 ispitanika (8,8\%), neformalno obrazovanje kursevi, obuke identifikovano kod 11 ispitanika $(4,2 \%)$ i radno iskustvo kod 225 ispitanika (86,5\%). Iz ovog prikaza upečatljivo je da vlasnici/menadžeri/preduzetnici malih preduzeća najveće poverenje i zasluge dodeljuju radnom iskustvu kao izvoru menadžment znanja koje poseduju.

Dostupnost neformalnog obrazovanja i njegova posećenost od strane ispitanika u uzorku predstavljena je u narednoj tabeli. Prema raspoloživim podacima neformalnoj obuci prisustvovalo je 87 ispitanika (33,5\%) dok su se u 173 (66,5\%) slučaja ispitanici izjasnili da nisu pohađali neformalno obrazovanje na temu menadžmenta i vođenja sopstvenog posla. 


\begin{tabular}{|c|c|c|c|c|}
\hline & Učestalost & Procenat & $\begin{array}{c}\text { Validni } \\
\text { procenat }\end{array}$ & $\begin{array}{c}\text { Kumula- } \\
\text { tivni } \\
\text { procenat }\end{array}$ \\
\hline $\begin{array}{c}1 \text { Formalnoobra- } \\
\text { zovanje }\end{array}$ & 23 & 8,8 & 8,8 & 8,8 \\
\hline $\begin{array}{c}2 \text { Neformalnoobra- } \\
\text { zovanje - kursevi, } \\
\text { obuke }\end{array}$ & 11 & 4,2 & 4,2 & 13,1 \\
\hline 3 Radnoiskustvo & 225 & 86,5 & 86,5 & 99,6 \\
\hline $4 \begin{array}{c}\text { Ne posedujemznan- } \\
\text { je o upravljanju }\end{array}$ & 1 &, 4 &, 4 & 100,0 \\
\hline Ukupno & 260 & 100,0 & 100,0 & \\
\hline
\end{tabular}

čiti da su ispitanici uglavnom saglasni sa potrebom posedovanja menadžmet znanja. Kada je u pitanju opredeljenje u odnosu na eksternu menadžment pomoć, koje se ispituje varijablom C3a.12, srednja vrednost iznosi 3,89 (na skali od 1 do 5, gde je 1 netačno, a 5 tačno) dok je standardno odstupanje od srednje vrednosti 1,174, iz čega se može zaključiti da su vlasnici/ preduzetnici/menadžeri malih preduzeća neodlučni po pitanju potrebe za menadžment znanjem izvan preduzeća. Takođe, sličnog opredeljenja su i po pitanju varijable C3a.13 koja ispituje spremnost vlasnika/preduzetnika/menadžera za finansiranje eksternih menadžment usluga čija srednja vrednost iznosi 3,86 (na skali od 1 do 5 , gde je 1 netačno, a 5 tačno) dok je standardno odstupanje od srednje vrednosti 1,278.

Pored toga što opisni statistički pokazatelji varijabli pruža-

Tabela 2. Znanje o menadžmentu stekao sam kroz

Izvor: Kalkulacija autora

Koliko je razvijena svest vlasnika/preduzetnika/menadžera, odnosno u kojoj meri je prepoznata potreba za menadžment znanjem kao ključnom determinantom uspešnog poslovanja može se videti iz prikaza tabele 3 . Predstavljeni su opisni statistički pokazatelji, u ovom slučaju, naredne tri varijable koje su po prirodi kontinuirane promenljive. Kod varijable C3a.10 ispitanici se izjašnjavaju o potrebi posedovanja stručnog znanja o samostalnom upravljanju i vođenju sopstvenog preduzeća, srednja vrednost varijable C3a.10 iznosi 4,25 (na skali od 1 do 5 , gde je 1 netačno, a 5 tačno) dok je standardno odstupanje od srednje vrednosti 1,034. Iz dobijenog rezultata možemo zakljuju proste informacije možemo zaključiti da je svest o potrebi i značaju menadžment znanja za uspešno vođenje malih preduzeća na veoma niskom nivou i predstavlja područje skrivenih mogućnosti i značajnih rezervi za unapređenje efikasnosti ovog sektora privrede, što ćemo ispitati korišćenjem složenih statističkih postupaka u narednom delu rada.

Naredni segment posvećen je osnovnoj istraživačkoj nameri koja je usmerena na ispitivanje odnosa učinka/uspeha malih preduzeća i obima i strukture menadžment aktivnosti. Pre nego što se pređe na testiranje osnovne istraživačke pretpostavke izvršiće se preliminarna ocena odnosa dve grupe varijabli pomoću koeficijenta Pearsonove korelacije jer smatramo da će se obezbediti značajan ishod u vidu upotrebljivih informacija za analizu koja je planirana u okviru postavljene hipoteze.

\begin{tabular}{|c|c|c|c|c|c|c|c|c|c|c|c|c|}
\hline & \multirow{2}{*}{ N } & \multirow{2}{*}{$\begin{array}{l}\text { Range } \\
\text { Stat }\end{array}$} & \multirow{2}{*}{$\begin{array}{l}\text { Min } \\
\text { Stat }\end{array}$} & \multirow{2}{*}{$\begin{array}{l}\text { Max } \\
\text { Stat }\end{array}$} & \multicolumn{2}{|c|}{ Sred. Vred. } & \multirow{2}{*}{$\begin{array}{l}\text { Std. } \\
\text { dev. }\end{array}$} & \multirow{2}{*}{$\begin{array}{c}\text { Varija- } \\
\text { nsa }\end{array}$} & \multicolumn{2}{|c|}{ Izduženost } & \multicolumn{2}{|c|}{ Spljoštenost } \\
\hline & & & & & Stat & $\begin{array}{l}\text { Std. } \\
\text { grešk }\end{array}$ & & & Stat & $\begin{array}{c}\text { Std. } \\
\text { greška }\end{array}$ & Stat & $\begin{array}{l}\text { Std. } \\
\text { greška }\end{array}$ \\
\hline $\begin{array}{l}\mathrm{C} 3 \mathrm{a} .10 \mathrm{~V} / \mathrm{P} / \mathrm{M} \text { je potrebno strucno znanje o } \\
\text { samostalnom upravljanju sopstvenog posla? }\end{array}$ & 260 & 4 & 1 & 5 & $\underline{4,25}$ & 0,064 & 1,034 & 1,069 & $-1,679$ & 0,151 & 2,547 & 0,301 \\
\hline $\begin{array}{l}\text { C3a.12 V/P/M malih preduzeća trebaju } \\
\text { eksternu pomoć za sticanje znanja o upravl- } \\
\text { janju sopstvenim poslom? }\end{array}$ & 260 & 4 & 1 & 5 & $\underline{3,89}$ & 0,073 & 1,174 & 1,378 & $-1,160$ & 0,151 & 0,649 & 0,301 \\
\hline $\begin{array}{l}\text { C3a.13 Za eksterne usluge obrazovanja VPM } \\
\text { spreman sam izdvojiti odredjena finan. } \\
\text { sredstva }\end{array}$ & 260 & 4 & 1 & 5 & $\underline{3,86}$ & 0,079 & 1,278 & 1,633 & $-1,114$ & 0,151 & 0,218 & 0,301 \\
\hline Valid N (listwise) & 260 & & & & & & & & & & & \\
\hline
\end{tabular}

Tabela 3. Opisni statistički pokazatelji grupe varijabli

Izvor: Kalkulacija autora

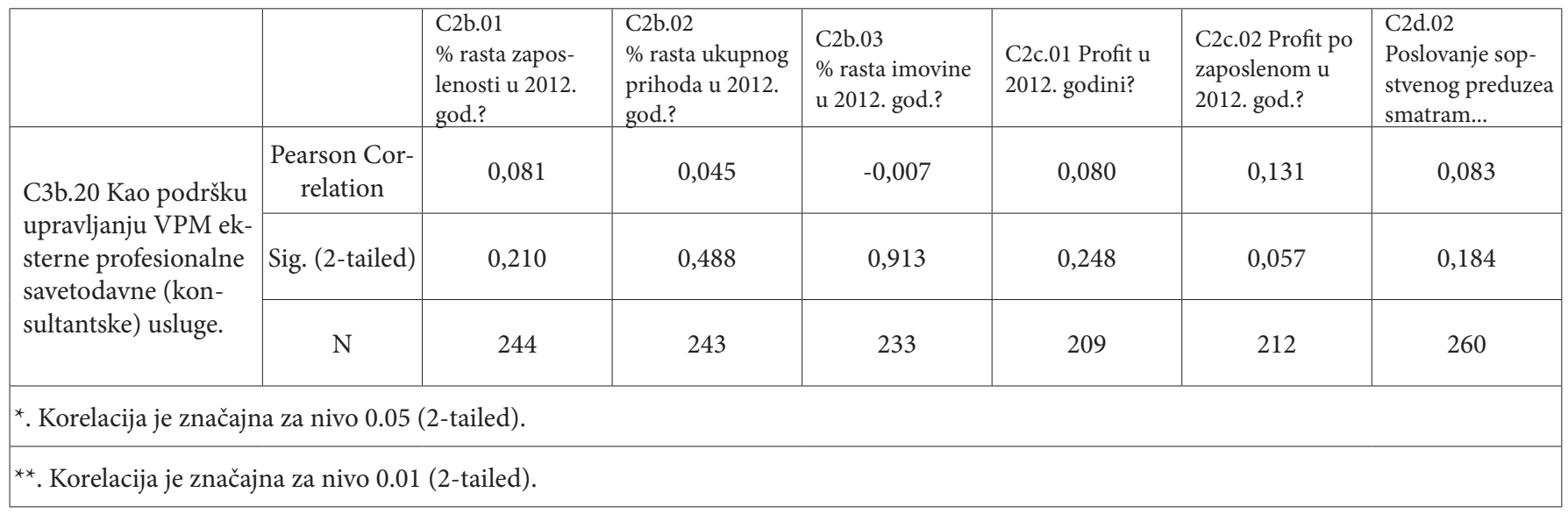

Tabela 4. Korelacija kriterijuma uspeha/učinka i definisanih varijabli menadžment prakse Izvor: Kalkulacija autora 
Podaci predstavljeni u prethodnoj tabeli rezultat su korelacione analize odnosa dve grupe varijabli i to varijabli menadžment prakse i varijabli učinka/uspeha. Opštim pregledom može se zaključiti da su rezultati ujednačeni po pitanju prirode i jačine veze, odnosno dominantna je pozitivna korelaciona veza male jačine između stepena zastupljenosti menadžment aktivnosti i indikatora uspeha/učinka malih preduzeća. Njene pojedinosti u okviru ove namere nemaju posebnu relevantnost, te su stoga izostavljene iz rada. To konkretno znači da preduzeća odnosno vlasnik/preduzetnik/menadžer koji imaju veći stepen primene menadžment prakse ostvaruju i veći uspeh/učinak u poslovanju. Takođe, veoma je značajan izuzetak po pitanju rezultata ove korelacione analize koji se javlja kod varijble C3b.09 Odluke u preduzeću donosi isključivo vlasnik/preduzetnik/menadžer bez prenošenja nadležnosti na saradnike/zaposlene, odnosno pitanja stepena centralizacije i učestalosti delegiranja. Negaivna korelaciona veza između pomenute menadžment aktivnosti i svih indikatora učinka ukazuje da vlasnici/preduzetnici/menadžeri koji su formirali centralizovani sistem odlučivanja sa manjim stepenom delegiranja poslova ostvaruju manji uspeh/ učinak. Upravo ovaj rezultat potvrđuje relevantnost i pouzdanost metodologije istraživanja, odnosno upitnika, definisanog uzorka ciljne grupe ispitanika ali i značaj dobijenih rezultata.

\section{REZIME}

Angažovanje i upućenost vlasnika/preduzetnika/menadžera malih preduzeća na eksternu menadžment podršku predstavlja realnu potrebu u okviru ove faze razvoja prevashodno zbog ograničenih resursa, pogotovo ljudskih i nedostatka profesionalnih menadžera. Nastojanja vlasnika/preduzetnika/menadžera da budu bolji izvršioci nego menadžeri kao i okolnosti rada u većini malih preduzeća sa malim brojem zaposlenih ne pružaju dovoljno prilike vlasniku/preduzetniku/menadžeru za razmenu ideja i iskustava kao ni za grupno rešenje problema, ali su zbog osećaja usamljenosti upućeni na traženje pomoći van svoje organizacije. Jedna od glavnih prednosti spoljnih izvora menadžerske pomoći jeste nepristrasnost i objektivan pristup u pronalaženju potrebnih rešenja ili ideja na bazi metoda i pristupa koji su posledica praktičnog preduzetničkog i menadžerskog iskustva. Osnovni zaključak koji proizilazi iz sprovedenog istraživanja i prezentovanih rezultata ogleda se u sledećem:

prisutna je svest o potrebi menadžment prakse u malim preduzećima kao i spremnost za prihvatanje eksterne menadžment podrške;

postoji minimalna pozitivna korelacija između visoko pouzdanih indikatora uspeha/učinka malih preduzeća i eksterne menadžment prakse u malim preduzećima,ali ona nije statistički značajna.

Ovi rezultati upućuju na zaključak da mala preduzeća ne koriste u velikoj meri eksterne usluge profesionalnog menadžmenta, čime značajno utiču na potencijal rasta i uspeh/učinak malih preduzeća.

\section{LITERATURA}

Ansoff, H.I. (1991). Critique of Henry Mintzberg's"The design school: reconsidering the basic premises of strategic planning". Strategic Management Journal, 12(6), 449-461.

Armstrong, J. S. (1982). The value of formal planning for strategic decisions: review of empirical research. Strategic $\mathrm{Ma}$ nagement Journal, 3(3), 197-211.

Brinkmann, J., Grichnick, D., Diana, K., (2010), Should entrepreneurs plan or just storm the castle? A meta-analysis on contextual factors impacting the business planning-performance relationship in small firms, Journal of Business Venturing 25 (1) 24-40.

Hamdani, D. (2006). Conceptualizing and measuring business incubation. Ottawa: Statistics Canada, Science, Innovation and Electronic Information Division.

Hamdani, D. (2006). Conceptualizing and measuring business incubation. Statistics Canada, Science, Innovation and Electronic Information Division.

Hills, G. (1988). Variations in university entrepreneurship education: an empirical study of an evolving field. Journal of Business Venturing, 3(2), 109-122.

Honig, B. (2004).Entrepreneurship education: toward a model of contingency-based business planning. Academy of $\mathrm{Ma}$ nagement Learning \& Education, 3(3), 258-273.

Lange, J.E., Mollov, A., Pearlmutter, M., Singh, S., \& Bygrave, W.D. (2007). Pre-start-up formal business plans and poststart-up performance: a study of 116 new ventures. Venture Capital, 9(4), 237-256.

Lumpkin, J.R., \& Ireland, R.D. (1988). Screening Practices of New Business Incubators: The Evolution of Critical Success Factors. American Journal of Small Business, 12(4), 5981.

Mintzberg, H. (1994). The Rise and Fall of Strategic Planning. New York: The Free Press.

Mosakowski, E. (1997). Strategy making under causal ambiguity: conceptual issues and empirical evidence. Organization Science, 8(4), 414-442.

Porter, M.E., \& Schwab, K. (2009). The Global Competitiveness Report 2008-2009. Dostupno na: http://www.weforum. org/reports/global-competitiveness-report-2008-2009

Russell, R., Atchison, M., \& Brooks, R. (2008). Business plan competitions in tertiary institutions: encouraging entrepreneurship education. Journal of Higher Education Policy \& Management, 30(2), 123-138.

Službeni glasnik Republike Srbije. (2010). Zakon o računovodstvu i reviziji. Službeni glasnik RS”, br. 46/06 i 111/09. Dostupno na: http://www.mfin.gov.rs/pages/article. php?id=7127

Wickham, P. A. (2006). Strategic entrepreneurship. Harlow, England: Financial Times Prentice Hall.

Wiltbank, R., Dew, N., Read, S., \& Sarasvathy, S.D. (2006). What to do next? The case for non-predictive strategy. Strategic Management Journal, 27 (10), 981-998. 